\title{
The burrow system of the common vole (M. arvalis, Rodentia) in Switzerland
}

\author{
Andrea Brügger, Wolfgang Nentwig and Jean-Pierre \\ Airoldi* \\ Institute of Ecology and Evolution, University of Bern, \\ Baltzerstrasse 6, CH-3012 Bern, Switzerland, \\ e-mail: airoldi@iee.unibe.ch \\ *Corresponding author
}

\begin{abstract}
Fifty burrow systems of Microtus arvalis were excavated, from October 2006 to August 2007 in wildflower fields and quasi-natural habitats in five areas near Bern, Switzerland. They comprise an aboveground part, which is longer in spring/summer, and a subterranean part, which is longer in autumn/winter. Three main construction types exist: (a) linear burrows, (b) compact and tight networks, and (c) structures containing both a compact network around the nest and linear parts elsewhere. The subterranean length was on average $16.9 \mathrm{~m}$ (range: $0.5-70.2 \mathrm{~m}$ ) and aboveground length $39.4 \mathrm{~m}$ (range: 0-95 m). Numbers of intersections, dead ends, and openings correlate significantly with subterranean burrow length. Nests and food caches were located at a maximal depth and mostly in a central position, as revealed by graph theory.
\end{abstract}

Keywords: burrow centre; eccentricity; graph theory; habitat; Microtus arvalis; season.

\section{Introduction}

In addition to habitat and food supply, burrow systems represent the most important environmental factor for Microtus arvalis (Pallas 1779), because they spend most of their life in these systems, where they build their nests and raise their young (Mackin-Rogalska et al. 1986). The subterranean burrows are used to forage and store food; they also protect the voles from predators and extreme environmental conditions. Aboveground paths lead to feeding places, short escape tunnels, and openings of the burrow system. They allow fast and safe movement as well as orientation in space (Leicht 1979).

Burrow systems and burrowing behaviour in subterranean small mammals (Insectivores and Rodents) have been reviewed by Dubost (1968), Hickman (1989), Reichman and Smith (1990) and Nevo (1999). Detailed descriptions exist for only a few species and most studies include small sample sizes of incompletely excavated systems from a few habitats, representing a small portion of range during certain times of the year (Hickman, 1989).

Habitat type, season, and inhabitants are known to have an influence on burrow systems of fossorial species. Previous studies show that factors relating to habitat are mainly vegetative cover and food supply; the same plants that provide food for the voles often also supply them with cover, so it is difficult to separate the effects of these two factors (Ostfeld 1985). Soil density might influence burrow systems of Microtus arvalis and other species. Burrows of pocket gophers decrease in length and area as the hardness of soil increases (Romanach et al. 2005). Laundre and Reynolds (1993) observed an effect of soil quality on the geometry of burrows in five different species. The second main factor influencing burrow structure is season. In M. arvalis small burrows are expected to be unsuitable for winter survival because of the lack of food caches, a greater likelihood of flooding, reduced insulation, and a greater exposure to predation (Boyce and Boyce 1988). The third main factor influencing burrow structure is the inhabitants. Mankin and Getz (1994) report that a burrow can have very different structures depending on the number of inhabitants.

Another important point in the structure of a burrow system was already studied by Airoldi and De Werra (1993) in Arvicola terrestris, namely the importance of the situation of nest(s) within a burrow for animals living underground. A central location, in a graph theoretical sense, can be reached very quickly and easily from everywhere in the burrow system. Based on previous studies we expect nests and food chambers to be placed near a centre.

Habitat type (mainly vegetation and soil density) as well as the seasons are likely to influence Microtus arvalis burrow geometry. Size and complexity were expected to increase from spring to autumn and winter. The purpose of the present study is to shed light on different aspects of the burrow system of a semi-fossorial species.

\section{Materials and methods}

\section{Study area}

The fieldwork was conducted from October 2006 to August 2007 in quasi-natural habitats and wildflower fields and strips. Quasi-natural habitats are undisturbed areas such as railway slopes and nature reserves where the dominating plant species were always grasses (Poaceae). Wildflower fields are so-called ecological compensation areas, sown with a mixture of wild plants to enhance biodiversity (Heitzmann and Nentwig, 1993). Their purpose is to replace or compensate for natural areas lost to agriculture or urbanization. We also worked in a third type of habitat, i.e., wildflower fields 
still containing some of the typical sown wild plants, but completely overgrown and dominated by grasses. Burrow systems were excavated in 17 different locations: 9 wildflower fields, 4 quasi-natural habitats, and 4 different wildflower fields overgrown and dominated by grasses. They were situated near Bern, Switzerland, in the following localities: Riedbach, Niederwangen, Uettligen, Schönbühl, Zollikofen.

Four categories of soil density were defined: $1=$ very soft and sandy, $2=$ soft, $3=$ hard, and $4=$ very hard with many stones and/or roots.

\section{Burrow excavation and analysis}

For the excavation of the burrow systems, the same methodology as in Airoldi (1976) was used. The prospected area was delimited with $50 \mathrm{~cm}$ long metal rods, tucked vertically into the soil $1 \mathrm{~m}$ apart. Then, all aboveground paths and openings were mapped on millimetre paper to a scale of 1:50. We started the excavation at one opening in the delimited area and dug out the subterranean tunnels and chambers by hand or with small tools (e.g., shovels). Nests, food caches, latrines, and other chambers were labelled and the nests were drawn to a scale of 1:20. The depths of all subterranean tunnels (bottom of gallery) and chambers were measured at intervals of approximately $30 \mathrm{~cm}$. A total of 26 burrow systems was excavated in wildflower fields or strips,
15 in quasi-natural habitats and nine in wildflower fields dominated by grasses.

Tunnel length was measured with a curvimeter on the map, the area of the system was evaluated by counting all onequarter square meters crossed by tunnels or aboveground paths. The percentage of tunnels deeper than $15 \mathrm{~cm}$ below ground was calculated, as well as the maximum, minimum, and average depths of the whole burrow system. To analyse the structure, we counted the number of dead ends, openings, intersections, and cyclic structures of each burrow. In addition, the numbers of nests, food caches, and other chambers were counted and their depths recorded.

\section{Graph theory}

For each mapped subterranean burrow system, the vertices (intersections and endings) were numbered and the lengths between them, or edges, were measured with a curvimeter and rounded to the nearest multiple of $5 \mathrm{~cm}$. The measured lengths were represented in the form of a matrix with the vertices $A_{\mathrm{i}}, A_{\mathrm{j}}$ and the edge $L_{\mathrm{ij}}$ connecting them. The sum of edges equals the total length of the burrow, which was therefore measured in two different ways: (a) one operation (curvimeter), (b) sum of edges. The results were very similar and the discrepancies were mostly owing to the rounding off used in the second method. The matrix with all edges connecting the different vertices of a burrow system was then

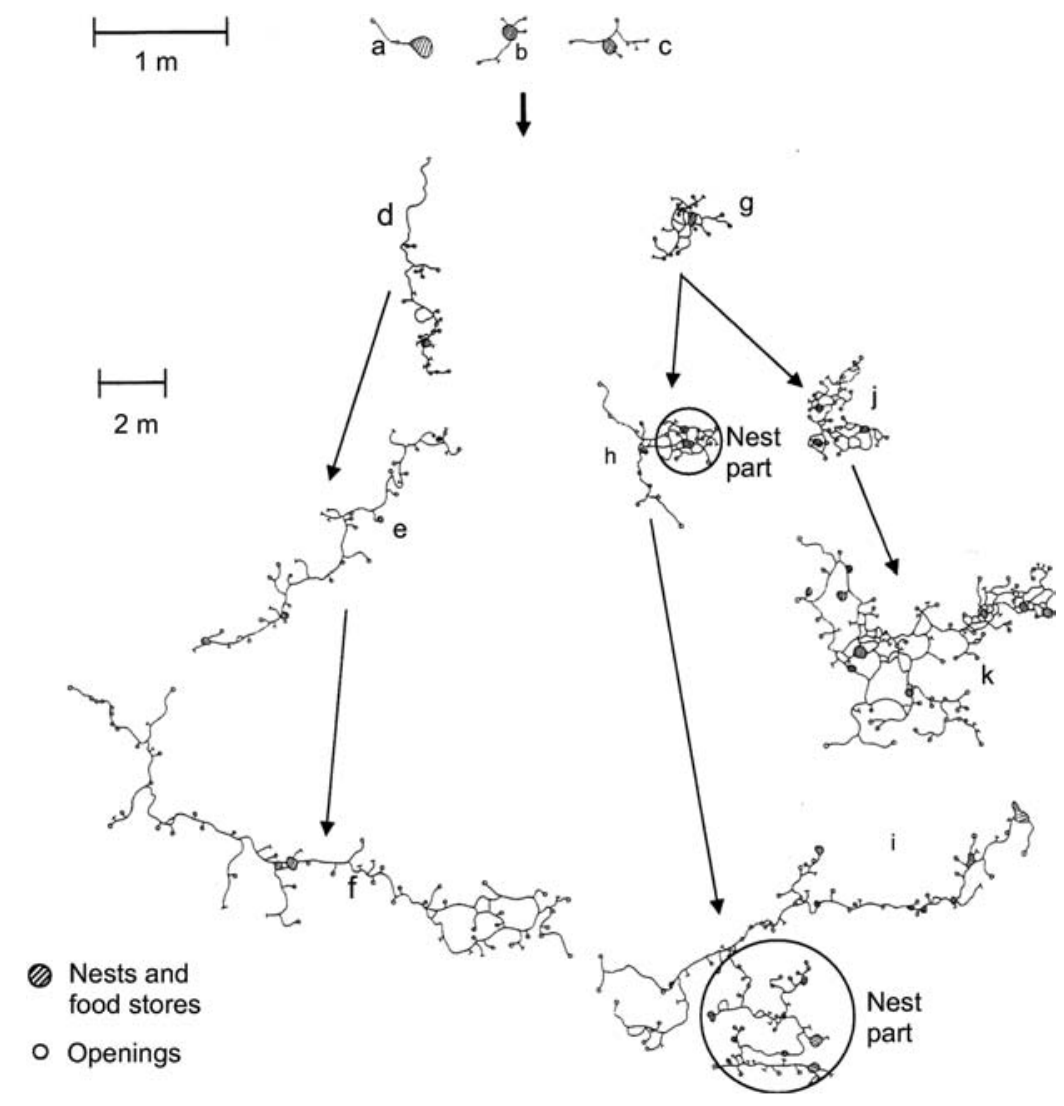

Figure 1 Different excavated burrow systems and possible ways of development. a, b, c: beginning stages of burrow construction; d, e, $\mathrm{f}$ : linear structures; $\mathrm{j}$, k: compact network structures; h, i: mixture of linear and compact structures. 
entered in a graph theoretical computer programme (Airoldi and De Werra 1993) to compute the shortest path between any two vertices, the centre(s) of the graph, and the relative eccentricities of all vertices of a burrow. The centre in a graph theoretical sense is that vertex closest to any other vertex within the burrow system; there could be more than one centre. The relative eccentricity of a vertex is the quotient of its distance to the centre and the distance to the centre of the most remote (or eccentric) vertex. It can take values from 0 to 1 , where 0 represents a central vertex and 1 a vertex at maximum distance from the centre. Relative eccentricities allow the comparison of burrows, independently of their size. A nest or food space was considered central, when its relative eccentricity was smaller than the median relative eccentricity of all vertices in the burrow. All calculations were based either on real distance (RD) in $\mathrm{cm}$ between two vertices or the number of edges (NEs) between them. RDs are related to the time spent by the animal on the move, or the energy expended when moving from one point to another. The NEs represent the number of decisions (turn left or right) a vole has to make when moving from one point to another (Airoldi and De Werra 1993).

\section{Statistical analysis}

To test for correlation between two factors, we used Spearman Rank correlation $\left(\mathrm{r}_{\mathrm{S}}\right)$ with the statistic programme PAST (Hammer et al. 2001) and also JMP, version 6.0.0, SAS Institute Inc., Cary, NC, USA (2005). Effect size was computed according to Cohen (1988).

\section{Results}

\section{Geometry of the burrow systems}

Three main construction types of burrow systems emerged (Figure 1): long drawn-out and linear burrows (d, e, f), compact and tight burrows $(\mathrm{g}, \mathrm{j}, \mathrm{k})$, and burrows comprising both compact and linear parts $(\mathrm{h}, \mathrm{i})$. The excavated burrows differed widely in their dimensions and structure. The largest burrow had a subterranean length of $70 \mathrm{~m}$, the shortest of only $0.5 \mathrm{~m}$, the average being $16.9 \mathrm{~m}$ (Table 1 ). The average length of aboveground paths was approximately $40 \mathrm{~m}$, but maximum lengths up to $95 \mathrm{~m}$ and minimum of less than $2 \mathrm{~m}$ were found. Some burrows had no aboveground paths. The average density of subterranean tunnels $\left(2.2 \mathrm{~m} / \mathrm{m}^{2}\right)$ was higher than that of aboveground paths $\left(1.8 \mathrm{~m} / \mathrm{m}^{2}\right)$ and ranged from a maximum of $4 \mathrm{~m} / \mathrm{m}^{2}$ (very dense and compact burrow systems) to a minimum of $0.8 \mathrm{~m} / \mathrm{m}^{2}$ (very linear burrow systems) (Table 1). The subterranean tunnel density was negatively correlated with soil density; in very hard soil with many roots and stones the value was much lower than in soft soil $\left(\mathrm{r}_{\mathrm{s}}=-0.43, \mathrm{p}=0.002, \mathrm{n}=50\right)$.

Subterranean and aboveground lengths were both highly correlated with the subterranean area $\left(\mathrm{r}_{\mathrm{S}}=0.98, \mathrm{p}<0.0001\right.$, $\mathrm{n}=50)$ and aboveground area $\left(\mathrm{r}_{\mathrm{s}}=0.98, \mathrm{p}<0.0001, \mathrm{n}=50\right)$, respectively. The average depth was $12.6 \mathrm{~cm}$ (maximum of $44 \mathrm{~cm}$ and minimum of $2 \mathrm{~cm}$, Table 1). Most subterranean burrow systems were built on one level only, but in some, a deeper, second level was present. The depth of a burrow was negatively correlated with soil density $\left(r_{s}=-0.31, p=0.028\right.$,

Table 1 Average values, standard errors and ranges of dimension, structure and chamber parameters of all excavated burrow systems $(\mathrm{n}=50)$.

\begin{tabular}{|c|c|c|c|c|c|}
\hline Parameters & Average $\pm \mathrm{SE}$ & Range & $\begin{array}{l}\text { Spring/summer } \\
(\mathrm{n}=32)\end{array}$ & $\begin{array}{l}\text { Autumn/winter } \\
(\mathrm{n}=18)\end{array}$ & Cohen's d \\
\hline Length, subterranean (m) & $16.9 \pm 2.2$ & $0.5-70.2$ & $13.2 \pm 2.8$ & $23.4 \pm 2.8$ & 0.71 \\
\hline Length, aboveground (m) & $39.4 \pm 3.6$ & $0-95$ & $45.7 \pm 4.4$ & $28.1 \pm 5.2$ & 0.79 \\
\hline Area, subterranean $\left(\mathrm{m}^{2}\right)$ & $7.5 \pm 1.0$ & $0.5-28.8$ & & & \\
\hline Area, aboveground $\left(\mathrm{m}^{2}\right)$ & $19.6 \pm 1.6$ & $0-42.8$ & & & \\
\hline Area, total $\left(\mathrm{m}^{2}\right)$ & $24.0 \pm 1.5$ & $1.8-46.3$ & & & \\
\hline Tunnel density, subterranean $\left(\mathrm{m} / \mathrm{m}^{2}\right)$ & $2.2 \pm 0.1$ & $0.8-4$ & & & \\
\hline Tunnel density, aboveground $\left(\mathrm{m} / \mathrm{m}^{2}\right)$ & $1.8 \pm 0.04$ & $0-2.6$ & & & \\
\hline Tunnels deeper than $15 \mathrm{~cm}(\%)$ & $21.1 \pm 3.4$ & $0-88.5$ & & & \\
\hline Min. depth $(\mathrm{cm})$ & $5.7 \pm 0.3$ & $2-11$ & & & \\
\hline Max. depth (cm) & $24.1 \pm 1.1$ & $13-44$ & & & \\
\hline Average depth $(\mathrm{cm})$ & $12.6 \pm 0.5$ & $7-23.4$ & $13.1 \pm 0.7$ & $11.7 \pm 0.5$ & 0.42 \\
\hline Nests (n) & $1.1 \pm 0.1$ & $0-3$ & $1.2 \pm 0.1$ & $1.0 \pm 0.2$ & 0.32 \\
\hline Depth main nest $(\mathrm{cm})$ & $22.1 \pm 0.9$ & $12-37$ & $21.7 \pm 1.1$ & $22.9 \pm 1.4$ & 0.21 \\
\hline Entrances main nest (n) & $2.8 \pm 0.2$ & $1-6$ & & & \\
\hline Food caches $(\mathrm{n})$ & $0.8 \pm 0.2$ & $0-8$ & $0.7 \pm 0.2$ & $0.9 \pm 0.5$ & 0.14 \\
\hline Average depth of food caches $(\mathrm{cm})$ & $18.2 \pm 1.4$ & $10-34$ & & & \\
\hline Other chambers (n) & $0.8 \pm 0.2$ & $0-5$ & $0.5 \pm 0.2$ & $1.2 \pm 0.3$ & 0.59 \\
\hline Dead ends (n) & $6.7 \pm 0.9$ & $0-25$ & $4.7 \pm 0.8$ & $10.4 \pm 1.5$ & 0.81 \\
\hline Intersections (n) & $20.1 \pm 3.0$ & $0-124$ & $16.5 \pm 4.1$ & $26.3 \pm 3.8$ & 0.48 \\
\hline Cyclic structures (n) & $4.0 \pm 0.9$ & $0-40$ & $3.4 \pm 1.3$ & $4.9 \pm 1.2$ & 0.24 \\
\hline Openings (n) & $17.2 \pm 1.8$ & $2-58$ & $14.6 \pm 2.2$ & $21.9 \pm 2.9$ & 0.60 \\
\hline
\end{tabular}

Comparison of spring/summer and autumn/winter with Cohen's $d$ as a measure of effect size: large $(\geq 0.75)$, medium $(<0.75$ and $\geq 0.40)$, small $(<0.40$ and $\geq 0.15)$. 
$\mathrm{n}=50$ ). In very hard soil with many roots and stones, the burrow systems were on average less deep.

The burrow systems comprised on average 7 dead ends, 20 intersections, 4 cyclic structures, and 17 openings (Table 1). The larger the burrows, the more complex their structure. The correlations between subterranean length and number of dead ends $\left(r_{S}=0.83\right)$, intersections $\left(r_{S}=0.90\right)$, cyclic structures $\left(r_{S}=0.63\right)$ and openings $\left(r_{S}=0.84\right)$ were all highly significant $(\mathrm{p}<0.0001, \mathrm{n}=50)$. The largest burrow comprised up to 124 intersections, 40 cyclic structures, 25 dead ends, and 58 openings. The smallest burrows had no intersections, cyclic structures or dead ends and only two openings (Figure 1).

Only a few burrows contained no nest; most had one nest, some as many as three (Table 1). The depth of the main nest $(12-37 \mathrm{~cm}$, average $=22.1 \mathrm{~cm})$ was positively correlated with the maximum depth of the burrow system $\left(r_{S}=0.63\right.$, $p<0.0001, n=44)$. The average main nest had three entrances. The nesting material had a dry weight of $40-300 \mathrm{~g}$ and contained fine and dry grass, but also fresh plant material and other food remains. Many burrows contained food caches, mostly only one or two, but in some cases up to eight (Table 1). Plant remains found were grasses (Poaceae), Trifolium sp., Achillea millefolium and Daucus carota. The depth of the food caches averaged $18 \mathrm{~cm}$ (Table 1) and was also positively correlated with maximum depth of the burrow $\left(r_{s}=0.63, p=0.002, n=22\right)$. In addition to nests and food caches, there were also other, empty chambers with no clear function (Table 1). We found only one latrine with fresh excrements. A significant positive correlation was found between the number of food caches $\left(r_{S}=0.33, p<0.0001\right.$, $\mathrm{n}=50)$ or other chambers $\left(\mathrm{r}_{\mathrm{S}}=0.57, \mathrm{p}<0.0001, \mathrm{n}=50\right)$ and subterranean length.

The nest was mostly situated exactly at or near the centre of the whole burrow $(83.3 \%$ of all nests when calculated with $\mathrm{NE}, 73.8 \%$ when calculated with RD). In approximately onethird, the food caches were also centrally located.

\section{Factors influencing the geometry of burrow systems}

In Table 1 several burrow system features are compared between spring/summer and autumn/winter. The subterranean length is greater (Cohen's $d=0.71$ ) in autumn/winter than in spring/summer, whereas the aboveground length shows the opposite trend $(\mathrm{d}=0.79)$. The number of chambers other than food caches, as well as the number of dead ends ( $d=0.81)$, intersections $(d=0.48)$ and openings $(d=0.60)$, is greater in autumn/winter $(\mathrm{d}=0.59)$. Surprisingly, the average depth is higher in spring/summer $(\mathrm{d}=0.42)$.

When plotting the frequencies of the relative eccentricities based on RDs of all analysed burrow systems three different types of distributions appeared (Figure 2).

Type 1. Most vertices are very distant from the centre; there are few relative eccentricities close to 0 and many greater than 0.5 and near 1 (Figure 2). This situation is typical of linear burrow systems (Figure 1, d, e, f) mostly found in quasi-natural habitats, but also in a few wildflower fields.

Type 2. Most vertices are close to the centre; many relative eccentricities are near 0 and only few greater than 0.5 or
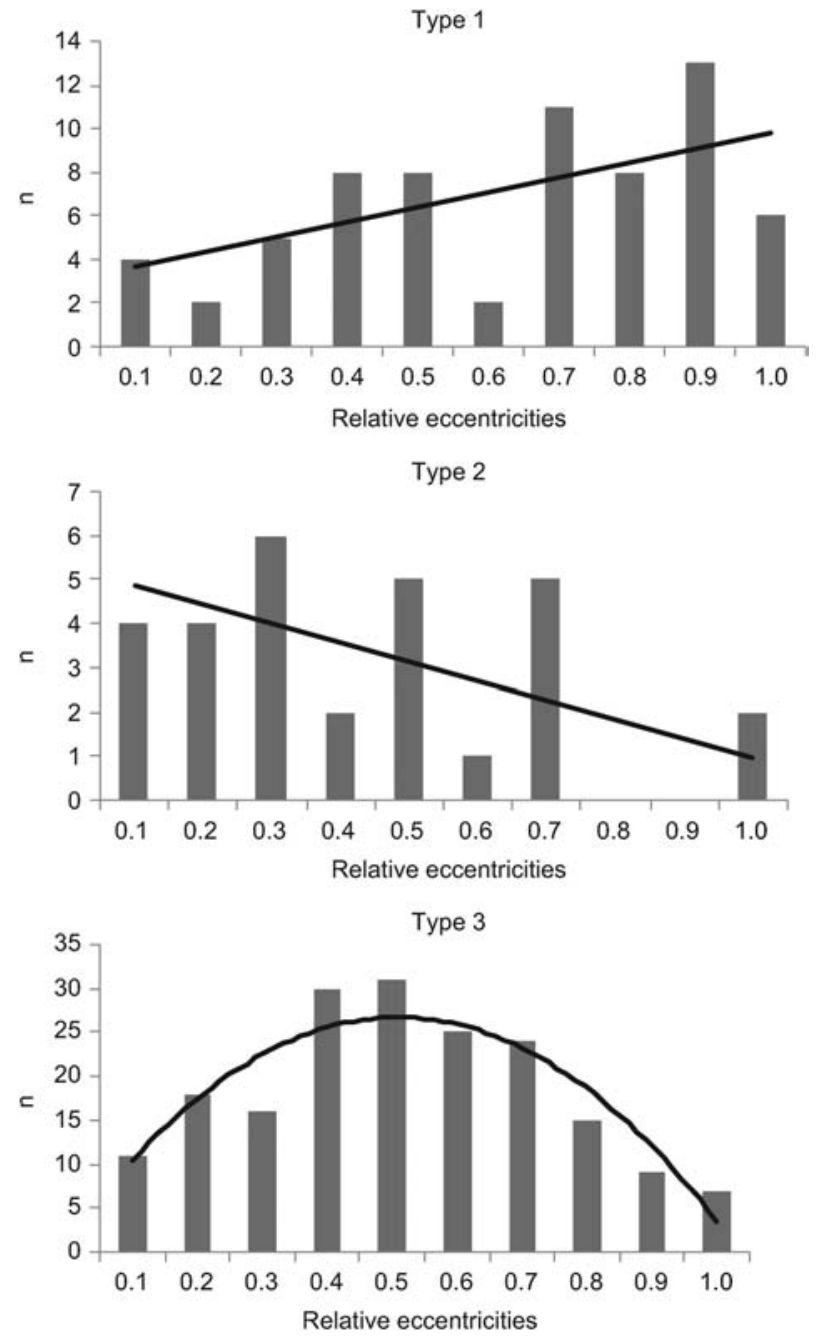

Figure 2 The three distribution types of relative eccentricities using RDs. The relative eccentricities are on the horizontal and the frequencies (n) on the vertical axis. Each class contains values up to the number indicated on the horizontal axis. The trend line was computed using Excel ${ }^{\circledR}$ (linear for types 1 and 2, and polynomial of degree 2 for type 3 ). Type 1 corresponds to burrow system e, type 2 to burrow $\mathrm{j}$ and type 3 to burrow $\mathrm{h}$ in Figure 1 .

near 1 (Figure 2). This situation occurred in compact networks of galleries (Figure 1, j, k) and was common in wildflower fields, but only rarely found in quasi-natural habitats.

Type 3. Most values are approximately 0.5 ; there are few relative eccentricities with values near 0 or 1 . Hence, there were few extremely central or distant vertices, most were situated in a median position (Figure 2). This occurred in burrows with a compact network around the nesting site and drawn-out linear parts leading away from the nest area (Figure $1, \mathrm{~h}, \mathrm{i}$ ). This type was very common in quasi-natural habitats and rare in wildflower fields.

In quasi-natural habitats most burrow systems showed a distribution of types 3 and sometimes 1 . In wildflower fields, all types of distributions were found, but type 2 was the most common. In wildflower fields dominated by grasses, distri- 
butions of type 1 and 2 were found, the latter being more common. Thus, a graph theoretical analysis supported our expectation that habitat has an influence on the construction type of burrow systems.

\section{Discussion and conclusions}

Although burrow systems show a great variety in geometry, three main construction types can be distinguished: linear structures, compact networks and a combination of the two. Independently of their construction type, most burrows had a dense and compact network around the nest. The nest appears to be similar in all burrows. It is the most important part of any burrow and the place where voles spend most of their time (Mackin-Rogalska et al. 1986). The several tunnels leading to the nest might be of advantage in making the nest easily reachable. Nests and food caches were mostly situated in the deepest parts of the whole burrow.

The comparison of burrow systems between spring/summer and autumn/winter shows that aboveground length is greater in summer and subterranean length is greater in winter. Voles tend to be more active above ground in spring/ summer than in autumn/winter. This is probably related to the denser vegetation cover, which offers better protection from predators, mainly raptors (Aschwanden et al. 2005). There are also more chambers, dead ends, intersections, cyclic structures, and openings in winter, leading to a generally more complex burrow system. These results should, however, be interpreted with caution, as other factors, such as habitat and soil, can also play a role, although we tried to sample similar numbers of each category in both seasons.

Graph theoretical analyses showed that whether using RDs or NEs between vertices, the nests lay in a central position, as expected, which according to optimal foraging theory makes good sense. A central position based on RD minimises travel time or, on NE, the number of decisions required for a vole to reach the nest.

Three main types of distribution of relative eccentricities can be distinguished related to the structure of burrow systems. In linear structures most eccentricities are greater than 0.5 , in burrows representing a dense network most eccentricities are near 0 and smaller than 0.5 , in mixed structures (dense network and linear parts) most eccentricities are approximately 0.5. Simulation models (Airoldi and De Werra, 1993) could be used to check under which conditions these different distribution types occur.

\section{Acknowledgements}

Thanks to Marc Lüthi for his help during fieldwork and to Peter Germann, Institute of Geography, University of Bern, for providing a short introduction to soil sciences. Comments and critiques by two anonymous reviewers were very helpful in improving our manu- script. Special thanks also go to all those who allowed us to work in their fields.

\section{References}

Airoldi, J.-P. 1976. Le terrier de la forme fouisseuse du campagnol terrestre, Arvicola terrestris scherman Shaw (Mammalia, Rodentia). Z. Säugetierk. 41: 23-42.

Airoldi, J.-P. and D. De Werra. 1993. The burrow system of the fossorial form of the water vole (Arvicola terrestris scherman Shaw) (Mammalia, Rodentia): an approach using graph theoretical methods and simulation models. Mammalia 57: 423-433.

Aschwanden, J., S. Birrer and L. Jenni. 2005. Are ecological compensation areas attractive hunting sites for common kestrels (Falco tinnunculus) and long-eared owls (Asio otus)? J. Ornithol. 146: 279-286.

Boyce, C.C.K. and J.L. Boyce. 1988. Population biology of Microtus arvalis. III. Regulation of numbers and breeding dispersion of females. J. Anim. Ecol. 57: 737-754.

Cohen, J. 1988. Statistical power analysis for the behavioral sciences (2nd edn). Lawrence Erlbaum, Hillsdale, NJ, 545 pp.

Dubost, G. 1968. Les mammifères souterrains. Rev. Ecol. Biol. Sol. 5: $135-197$.

Hammer, Ø., D.A.T. Harper and P.D. Ryan. 2001. PAST: Paleontological Statistics Software Package for Education and Data Analysis. Palaeontol. Electron. 4: 9.

Heitzmann, A. and W. Nentwig. 1993. Angesäte Ackerkrautstreifen in der Agrarlandschaft: Eine Möglichkeit zur Vermehrung des Nützlingspotentials und zur Kontrolle von Schädlings-Populationen, somit der Förderung der Biodiversität in der Kulturlandschaft, bei gleichzeitig intensiver landwirtschaftlicher Nutzung. Schweiz. Landwirtschaft. Forschung 32: 365-383.

Hickman, G.C. 1989. Adaptiveness of tunnel system features in subterranean mammal burrows. In: (Nevo, E. and O.A. Reig, eds) Evolution of subterranean mammals at the organismal and molecular levels. Alan R. Liss, Inc., New York. pp. 185-210.

Laundre, J.W. and T.D. Reynolds. 1993. Effects of soil-structure on burrow characteristics of 5 small mammal species. Great Basin Nat. 53: 358-366.

Leicht, W.H. 1979. Tiere der offenen Kulturlandschaft-Teil 2, Feldhamster, Feldmaus. Quelle and Meyer, Heidelberg. 264 pp.

Mackin-Rogalska, R., K. Adamczewska-Andrzejewska and N. Nabaglo. 1986. Common vole numbers in relation to the utilization of burrow systems. Acta Theriol. 31: 17-44.

Mankin, P.C. and L.L. Getz. 1994. Burrow morphology as related to social organization of Microtus ochrogaster. J. Mammal. 75: $492-499$.

Nevo, E. 1999. Mosaic evolution of subterranean mammals. Regression, progression and global convergence. Oxford University Press, Oxford. 413 pp.

Ostfeld, R.S. 1985. Limiting resources and territoriality in microtine rodents. Am. Nat. 126: 1-15.

Reichman, O.J. and S.C. Smith 1990. Burrows and burrowing behavior by mammals. In: (Genoways, H.H., ed.) Current mammalogy, Vol. 2. ISBN 0-306-43304-4. Plenum Press, New York. pp. 197-244.

Romanach, S.S., E.W. Seabloom, O.J. Reichman, W.E. Rogers and G.N. Cameron. 2005. Effects of species, sex, age, and habitat on geometry of pocket gopher foraging tunnels. J. Mammal. 86: $750-756$. 